\title{
Evaluation of Shear Bond Strenght of Porcelain to Cobalt-Chromium Alloy Fabricated with Different Methods after Thermocycling
}

\author{
Recep Kara*

\section{*Corresponding Author} \\ Recep Kara

\section{Article History} \\ Received: 23.12.2020 \\ Accepted: 02.01.2021 \\ Published: 14.01.2021
}

Dental Protheses Technologies Department, Istanbul Aydın University, Istanbul, Turkey

\begin{abstract}
Aim: This study aimed to mechanically test the shear bond strength (SBS) of cobalt-chromium (Co-Cr) metal frameworks prepared with three different production techniques with dental porcelain after the thermocycling process. Materials and Methods: Sixty Co-Cr-based metal substructure samples were prepared using traditional casting, $\mathrm{CAD} / \mathrm{CAM}$ system, and laser sintering methods. The samples were treated with uniform layering porcelain and half of the subgroups $(n=10)$ were thermocycling $\left(5000\right.$ cycles, $\left.5-55^{\circ} \mathrm{C}\right)$. Metal-ceramic bond strength of all samples was evaluated using the shear bond test under the standard. The shear bond strength values to the normal distribution was examined with an analysis program (SPSS for Windows 22.0, Chicago, IL, USA) was used for statistical analysis of the obtained data. One-way ANOVA test and post hoc test (Tukey's) performed for data evaluation. Results: A statistically significant difference was observed between the average bond strength $(\mathrm{MPa})$ in the comparison of different production techniques $(\mathrm{p}<0.05)$. The average bonding strength of the samples grouped according to different fabrication methods; was found $16.54 \pm 2.42 \mathrm{MPa}$ for the CAD/CAM milling method, $8.98 \pm 4.16 \mathrm{MPa}$ for selective laser sintering, and 8.76 $\pm 3.05 \mathrm{MPa}$ for conventional casting. When comparing the thermocycling application of the prepared samples, a statistically significant difference was found between the means of shear bond strength. The CAD/CAM milling group has the highest value $(15.54 \pm 2.16)$ and is statistically different from the others. Conclusions: According to the results of this study, it was determined that the production method affects the metal-ceramic bond strength, but the thermocycling application does not make a significant difference. Milled Co-Cr samples had a higher SBS value than casting and laser sintering samples.
\end{abstract}

Keywords: Co-Cr, CAD/CAM, laser sintering, shear bond strength, thermocycling.

\section{INTRODUCTION}

The metal-supported ceramic restorations and rehabilitation of missing teeth with prosthetic treatment is a frequently preferred treatment option in dentistry. The reasons why metal-ceramic restorations are still used with success today; their function, aesthetic and physical properties are satisfactory and their costs are low. Current developments in materials have also led to the development of metal-supported ceramic restorations. These developments include the development of new ceramics with higher physical properties and less wear than feldspathic porcelains, the use of newer metal alloy and ceramic combinations, and the use of press-on porcelains [1]. Recent studies investigating the bond strength of ceramic restorations with $\mathrm{Co}-\mathrm{Cr}$ metal substructures have focused on new production methods of metal infrastructures [2].

Today, lost wax and traditional casting methods are frequently used for the preparation of metal-based restorations. However, errors due to technical personnel at the laboratory stage, and difficulties experienced due to measurement and dental stone models can prevent ideal results in the preparation of metal infrastructures with this method. With technological developments, it is becoming increasingly common to use computer-aided designmanufacturing (CAD/CAM) technology for the rapid production of fixed restorations [3]. This manufacturing technology allows both the simplification of working methods and the use of newer and better materials. Compared to the traditional casting method, infrastructures can be processed and formed from prefabric blocks with the milling technique by using

Copyright (C) 2021 The Author(s): This is an open-access article distributed under the terms of the Creative Commons Attribution 4.0 International License (CC BY-NC 4.0) which permits unrestricted use, distribution, and reproduction in any medium for noncommercial use provided the original author and source are credited. 
these systems, which have advantages such as saving time as well as reducing costs and preventing problems during casting [4].

The reasons such as the excessive abrasion of the burs in milling technology, the failure of the system to provide the desired time savings, the excessive amount of residual material and the difficulty of producing more than one complex restoration at the same time, the use of "Rapid Prototype Production Techniques" in prosthetic dental treatment has recently been emphasized [5]. It carries out the physical production of three-dimensional models designed in the CAD unit by methods such as Selective Laser Sintering (SLS), Direct Metal Laser Sintering (DMLS), or Selective Laser Melting (SLM) [6]. With the ability of rapid prototype production techniques to make production by layering the material instead of removing the material from the main part, the shrinkage that occurs during casting processes is eliminated, objects with complex geometries can be produced easily and great cost savings are achieved compared to today's CAD/CAM systems [7].

In this study; To benefit the development of the metal-ceramic bonding, it was aimed to examine the bond strength of $\mathrm{Co}-\mathrm{Cr}$ metal infrastructures obtained by different production techniques with a uniform low-temperature porcelain system after the thermocycling process.

\section{MeTHODOLOGY}

The design of the metal framework was made in the Sketchup program. Stereolithography (STL) file of the designed framework was sent to the laboratory for fabricating (Fig-1a). Sixty Co-Cr samples were fabricated with the casting and the CAD/CAM and laser sintering methods. Casting samples were milled from wax blocks (MillStar Waxblank, S\&S Scheftner GmbH, Mainz, Germany) according to the virtual design and produced by the traditional casting method with cobalt-chromium Co-Cr powder (Starbond CoS Powder S\&S Scheftner GmbH, Mainz, Germany). Milled samples were milled from prefabricated disks (Starbond Easy Disk, S\&S Scheftner GmbH, Mainz, Germany) with a milling machine (Yena D40, Yenadent, İstanbul, Türkiye) (Fig-1b). Laser sintering samples produced with Eosint M270 system (EOS GmbH, Krailling, Germany) using Cr-Co alloy powder (EOS Cobalt Chrome SP2, EOS GmbH, Krailling, Germany). All samples were measured with a caliper and were adjusted to dimensions of $4 \times 5 \times 0.5 \mathrm{~mm}$. The standardized specimens were air-abraded and ultrasonically cleaned and divided into groups. The samples were sandblasted under 2 atm pressure with $110 \mu \mathrm{m} \mathrm{Al}_{2} \mathrm{O}_{3}$ particles at an angle of $45^{\circ}$ for 15 seconds at a distance of $10 \mathrm{~mm}$ for the samples whose leveling was completed. Opaque and dentin porcelain (Ceramco 3 Porcelain, Dentsply Sirona, Salzburg, Austria) was applied to the metal framework following the manufacturer's instructions and fired with a porcelain height of $4 \mathrm{~mm}$ (Fig 1c \& 2a). The prepared samples were divided into two groups according to the groups and they were subjected to a thermocycling process with a thermal cycler (MTE-101, MOD-Dental, Ankara, Türkiye).

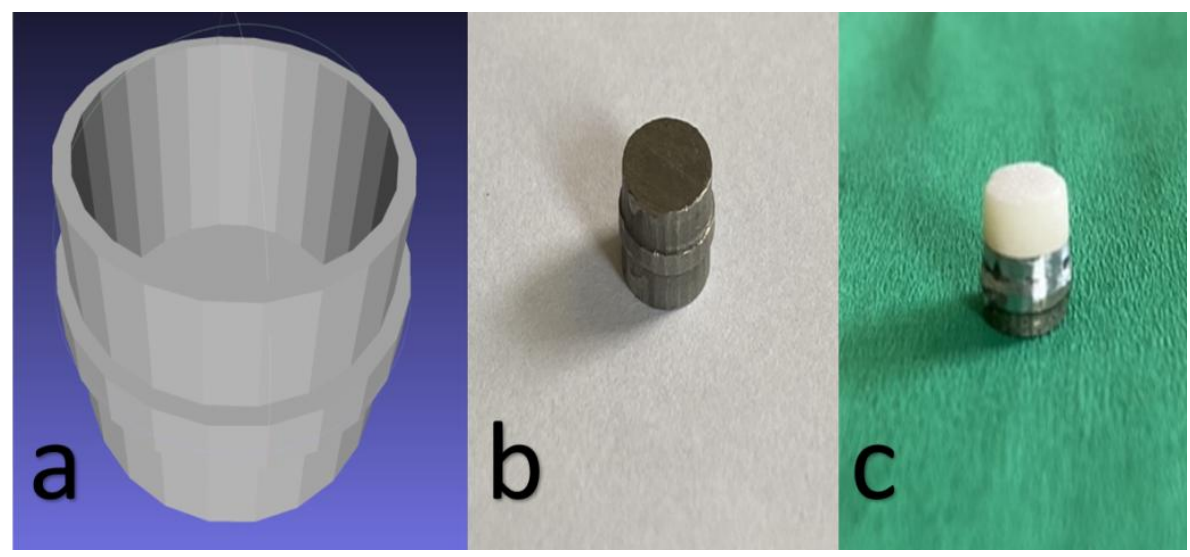

Fig-1a: STL file, b: Metal framework, c: Prepared sample 


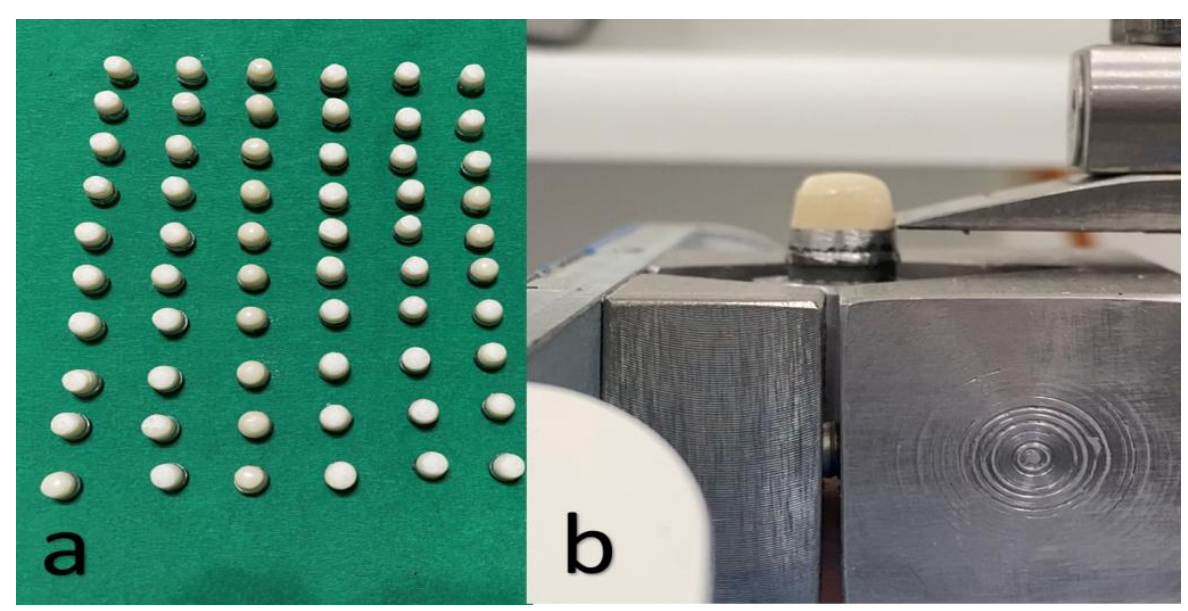

Fig-2a: Prepared samples, b:Universal test machine

All samples were embedded in acrylic resin. The acrylic embedded specimens were placed in the testing machine to apply the force of the single inclined chisel tip $1 \mathrm{~mm}$ away from the ceramic-metal interface (Fig-2b). The shear bond strength (SBS) was tested on a universal testing machine (MIC-101, MOD-Dental, Ankara, Turkey) at a crosshead speed of $1 \mathrm{~mm} /$ minute until separation occurred (Fig-2b). Maximum load failure samples were recorded and SBS values were calculated in units of megapascals (MPa).

An analysis program (SPSS 22.0, Chicago, IL, USA) was used for the statistical analysis of the data obtained. Mean and the standard deviation was used as descriptive statistics for the quantitative variables of this study determined by measurement. The One-Way ANOVA analysis was used for the comparison of the measurement values of more than two groups. Some post hoc tests were applied to find where the differences in the One-Way ANOVA result originated. Values at the level of $\mathrm{p}<0.05$ were considered significant.

\section{RESULTS}

A statistically significant difference was found between groups that did not apply thermocycling. Descriptive statistics of porcelain shear bond strength $(\mathrm{MPa})$ and multiple comparison test results between groups not applied are shown in Tables 1 and 2. In the comparison of the groups, a statistically significant difference was found between groups (Table-3). SBS value was higher in the milling group $(16.54 \pm 2.42)$ than casting $(8.76 \pm 3.05)$ and laser sintering $(9.86 \pm$ 4.16) group. Tables 4 and 5 show the bond strength (MPa) according to the subgrouping of the samples prepared with different production methods based on the thermocycling procedure. A statistically significant difference was found between the milling group $(15.54 \pm 2.16)$ and the others the thermocycling groups (Table 6). There was no statistical significance in the comparisons of the groups within themselves.

Table-1: Descriptives of non-thermocycling groups

\begin{tabular}{|c|c|c|c|c|c|c|c|c|}
\hline \multicolumn{9}{|c|}{ Мра } \\
\hline & \multirow[t]{2}{*}{$\mathrm{N}$} & \multirow[t]{2}{*}{ Mean } & \multirow[t]{2}{*}{$\begin{array}{l}\text { Std. } \\
\text { Deviation }\end{array}$} & \multirow[t]{2}{*}{$\begin{array}{l}\text { Std. } \\
\text { Error }\end{array}$} & \multicolumn{2}{|c|}{$\begin{array}{l}\text { 95\% Confidence Interval for } \\
\text { Mean }\end{array}$} & \multirow[t]{2}{*}{ Minimum } & \multirow[t]{2}{*}{ Maximum } \\
\hline & & & & & Lower Bound & Upper Bound & & \\
\hline $\mathrm{CG}$ & 10 & 8.76 & 3.05 & 0.96 & 6.58 & 10.95 & 4.05 & 13.52 \\
\hline MG & 10 & 16.54 & 2.42 & 0.76 & 14.80 & 18.28 & 11.54 & 20.29 \\
\hline LG & 10 & 8.96 & 4.16 & 1.31 & 5.98 & 11.94 & 2.69 & 15.70 \\
\hline Total & 30 & 11.42 & 4.86 & 0.88 & 9.60 & 13.24 & 2,69 & 20.29 \\
\hline
\end{tabular}

Table-2: ANOVA of non-thermocycling groups

\begin{tabular}{|l|l|l|l|l|c|}
\hline \multicolumn{7}{|c|}{ Mpa } \\
\hline & Sum of Squares & df & Mean Square & F & Sig. \\
\hline Between Groups & 393.61 & 2 & 196.80 & 18.11 & .00 \\
\hline Within Groups & 293.40 & 27 & 10.86 & & \\
\hline Total & 687.01 & 29 & & & \\
\hline
\end{tabular}


Recep Kara; South Asian Res J Oral Dent Sci; Vol-3, Iss-1 (Jan-Feb, 2021): 6-11

Table-3: Multiple comparisons of non-thermocycling groups

\begin{tabular}{|l|l|l|l|l|l|l|}
\hline \multicolumn{6}{|c|}{ Dependent Variable: Mpa } \\
\hline \multicolumn{7}{|c|}{ Tukey HSD } \\
\hline (I) groups & (J) groups & Mean Difference (I-J) & Std. Error & Sig. & 95\% Confidence Interval \\
\cline { 3 - 7 } & & & & & Lower Bound & Upper Bound \\
\hline \multirow{2}{*}{ CG } & MG & $-7.78^{*}$ & 1.47 & 0,00 & -11.43 & -4.12 \\
\cline { 2 - 7 } & LG & -0.19 & 1.47 & 0.99 & -3.85 & 3.45 \\
\hline \multirow{2}{*}{ MG } & CG & $7.78^{*}$ & 1.47 & 0.00 & 4.12 & 11.43 \\
\cline { 2 - 7 } & LG & $7.58^{*}$ & 1.47 & 0.00 & 3.92 & 11.23 \\
\hline \multirow{2}{*}{ LG } & CG & 0.19 & 1.47 & 0.99 & -3.45 & 3.85 \\
\cline { 2 - 6 } & MG & $-7.58^{*}$ & 1.47 & 0.00 & -11.23 & -3.92 \\
\hline \multirow{2}{*}{$*$ The mean difference is significant at the 0.05 level. } & & & \\
\hline
\end{tabular}

Table-4: Descriptives of thermocycling groups

\begin{tabular}{|l|l|l|l|l|l|l|l|l|}
\hline & N & Mean & $\begin{array}{l}\text { Std. } \\
\text { Deviation }\end{array}$ & $\begin{array}{l}\text { Std. } \\
\text { Error }\end{array}$ & & $\begin{array}{l}\text { 95\% Confidence Interval for } \\
\text { Mean }\end{array}$ & Minimum & Maximum \\
\cline { 1 - 5 } & & & & Lower Bound & Upper Bound & & \\
\hline CG & 10 & 8.03 & 2.61 & 0.82 & 6.16 & 9.90 & 4.16 & 12.42 \\
\hline MG & 10 & 15.54 & 2.16 & 0.68 & 13.99 & 17.09 & 11.53 & 19.19 \\
\hline Total & 10 & 8.54 & 3.78 & 1.19 & 5.83 & 11.25 & 3.59 & 14.70 \\
\hline
\end{tabular}

Table-5: ANOVA of thermocycling groups

\begin{tabular}{|l|l|l|l|l|l|}
\hline SBS (Mpa) & Sum of Squares & df & Mean Square & F & Sig. \\
\hline Between Groups & 352.37 & 2 & 176.18 & 20.42 & .00 \\
\hline Within Groups & 232.87 & 27 & 8.62 & & \\
\hline Total & 585.25 & 29 & & & \\
\hline
\end{tabular}

Table-6: Multiple comparisons of thermocycling groups

\begin{tabular}{|l|l|l|l|l|l|l|}
\hline \multicolumn{6}{|c|}{ Dependent Variable: Mpa } \\
\hline \multirow{2}{*}{ (I) groups } & $(\mathrm{J})$ groups & Mean Difference (I-J) & Std. Error & \multirow{2}{*}{ Sig. } & \multicolumn{2}{l|}{ 95\% Confidence Interval } \\
\cline { 3 - 7 } & & & & & Lower Bound & Upper Bound \\
\hline \multirow{2}{*}{ CG } & MG & $-7.51^{*}$ & 1.31 & 0.00 & -10.76 & -4.25 \\
\cline { 2 - 7 } & LG & -0.50 & 1.31 & 0.92 & -3.76 & 2.75 \\
\hline \multirow{2}{*}{ MG } & CG & $7.51^{*}$ & 1.31 & 0.00 & 4.25 & 10.76 \\
\cline { 2 - 7 } & LG & $7.00^{*}$ & 1.31 & 0.00 & 3.74 & 10.26 \\
\hline \multirow{2}{*}{ LG } & CG & 0.50 & 1.31 & 0.92 & -2.75 & 3.76 \\
\cline { 2 - 7 } & MG & $-7.00^{*}$ & 1.31 & 0.00 & -10.26 & -3.74 \\
\hline \multirow{2}{*}{$*$ The mean difference is significant at the 0.05 level. } & & & \\
\hline
\end{tabular}

The type of bond failure was visually examined with photographs made with a macro lens (Canon RF 24$105 \mathrm{~mm}$ f/4-7.1 IS STM Lens). If the separation occurred in the inner surface of the metal or ceramic itself, it was considered as cohesive, in the metal-ceramic junction area and the form of complete separation of the two materials from each other, as adhesive, and if both types of failure occurred together, it was considered as a mixed type separation. In Table-7, the frequency of the bonding failure types of metal-ceramic samples without thermocycling and in Table 8 are listed failure types in groups with thermocycling.

Table-7: Frequency of types of bonding failure in metal-ceramic samples without thermocycling

\begin{tabular}{|l|l|l|l|}
\hline \multirow{2}{*}{ Non-Thermocycling } & \multicolumn{4}{|l|}{ Failure type } \\
\cline { 2 - 4 } & Cohesive & Adhesive & Mix \\
\hline CG & 0 & 4 & 6 \\
\hline MG & 0 & 1 & 9 \\
\hline LG & 0 & 2 & 8 \\
\hline
\end{tabular}


Table-8: Frequency of types of bonding failure in thermocycling metal-ceramic samples

\begin{tabular}{|l|l|l|l|}
\hline \multirow{2}{*}{ Thermocycling } & \multicolumn{3}{|l|}{ Failure type } \\
\cline { 2 - 4 } & Cohesive & Adhesive & Mix \\
\hline CG & 0 & 4 & 6 \\
\hline MG & 0 & 3 & 7 \\
\hline LG & 0 & 2 & 8 \\
\hline
\end{tabular}

\section{DISCUSSION}

In this study, which examined the ceramic bond strengths of $\mathrm{Co}-\mathrm{Cr}$ metal infrastructures produced by three different methods after thermal cycling application, the ceramic bond strength of the samples obtained by the milling method showed statistically higher values compared to the samples obtained using the casting and laser sintering system. A statistically same significant difference was found between the average bond strength (MPa) in the grouping of the prepared samples depending on the thermocycling application.

Although many factors such as the castability of the alloy, the mechanical properties of the porcelain and metal alloy, the compatibility of the two materials, the design of the restoration and aesthetics are effective in the long-term clinical success of metal-supported porcelain restorations, the main thing in the success of the system is the formation of a strong connection between the metal and porcelain in a way that can withstand the stresses occurring in the mouth [8]. For this reason, it is seen that most of the studies on the success of metal-supported ceramic restorations in the literature focus on the metal-porcelain bonding $[9,10]$.

Bonding failure between metal and ceramic is a multifactorial problem related to the combination of different causes [11]. Coornaert et al., reported that the incidence of ceramic fractures in metal-supported ceramic restorations over 5 years of use is $1-3 \%$, and $5-10 \%$ over 10 years [12]. Although it is not possible to fully reflect the intraoral variables and the complexity of the oral environment to work under laboratory conditions, thermal cycling is an aging method used in in vitro studies to mimic these conditions [13].

De Vasconcellos et al., evaluated the effect of the firing temperature of the opaque layer and the thermal and mechanical aging procedure on the bond strength of a single type of dental ceramic supported with a Co-Cr metal substructure on the bonding strength of the opaque layer. They stated that the increase in the firing temperature of the opaque layer increased the bond strength, while the thermal and mechanical aging procedure did not make a significant difference in the bond strength [14].

Stawarczyk et al., three different Co-Cr-Mo alloy infrastructures (Ceramill Sintron; Milling, Ceramill NP L; Laser, Girobond NB; Casting) obtained by casting, milling, and laser sintering and subjected to thermal cycling. The bond strengths were examined with three different ceramics (Creation, VITA VM 13, Reflex). As a result of the study, the samples have similar bond strength values according to the construction methods; However, considering the relationship between ceramics and metal infrastructures, they found that Creation brand ceramics showed higher bond strength than VITA VM 13 and Reflex [15].

Serra-Prat et al., applied thermal cycling to half of the samples after processing porcelain (InLine, Ivoclar Vivadent, Schaan, Liechtenstein) using the layering technique on 90 pieces of Co-Cr metal substructure prepared in the form of cylinders by casting, milling, and laser sintering. They used the shear test method different from our study to evaluate the metal-ceramic bond strength of the samples in their work. As a result of this study, it was concluded that the ceramic bond strengths of metal infrastructures prepared by casting and milling method without thermal cycling were better than those obtained by laser sintering (casting: $42.79 \pm 14.14$, milling: $37.56 \pm 9.1$, laser sintering: $29.09 \pm 6.95$ ) [16]. In thermal cycling samples, there is a significant decrease in the ceramic bond strength of metal infrastructures prepared by casting and milling compared to the bond strength of the samples without thermal cycling, but there is no significant difference in the bond strength of metal infrastructures obtained by laser sintering and with and without thermal cycling (casting: $16.52 \pm 8.96$, milling: $22.21 \pm 13.25$, laser sintering: $24.28 \pm 10$ ). In this study, it is also stated that there is no difference in terms of connection failure types between the samples with and without thermal cycling [16].

Wang et al., evaluated the metal-ceramic bond strengths by subjecting $45 \mathrm{Co}-\mathrm{Cr}$ metal substructure samples $(25 \times 3 \times 0.5 \mathrm{~mm})$ prepared by laser sintering method using casting, milling, and laser device of Concept Laser to three points bending test after porcelain application. It was stated that VMK95 opaque and dentin ceramic belonging to the Vita company was applied to the samples that were subjected to the same roughening procedure as our pre-test study, different from our study. The average bond strength of the groups, which was obtained from the study, which was stated 
that there was a significant difference between the average bond strength of the casting and laser sintering groups, differ according to our study. (casting: $37.7 \pm 6.5$, milling: $43.3 \pm 9.2$, laser-sintered: $46.8 \pm 5.1$ ). The reason for this can be shown that the porcelain and casting used and the Co-Cr alloy brands in the milling method are different [17].

The high mechanical and physical properties of the block materials used in computer-aided production systems, which have a homogeneous structure due to their industrial production, as well as their reliability are important in the long-term success of the restorations produced [18].

\section{Conclusions}

The thermal aging process does not change the shear bond strength statistically between the groups. The SBS values obtained in the milling group are statistically different from those in the casting and laser groups.

It can be said that the reason why the milling group has a higher value compared to the other groups is due to the homogeneous structure of the infrastructure material used.

\section{REFERENCES}

1. Hama Suleiman, S., \& Vult von Steyern, P. (2013). Fracture strength of porcelain fused to metal crowns made of cast, milled or laser-sintered cobalt-chromium. Acta Odontologica Scandinavica, 71(5), 1280-1289.

2. Korkmaz, F. M., \& Aycan, S. (2019). Effect of fiber laser irradiation on the shear bond strength between acrylic resin and titanium. Scanning. 2019.

3. Kim, M. J., Choi, Y. J., Kim, S. K., Heo, S. J., \& Koak, J. Y. (2017). Marginal accuracy and internal fit of 3-D printing laser-sintered Co-Cr alloy copings. Materials (Basel). 10(1):1-13.

4. Sun, J., \& Zhang, F. Q. (2012). The Application of Rapid Prototyping in Prosthodontics. J Prosthodont. 21(8).

5. Santos, E. C., Shiomi, M., Osakada, K., \& Laoui, T. (2006). Rapid manufacturing of metal components by laser forming. International Journal of Machine Tools and Manufacture, 46(12-13), 1459-1468.

6. Roberts, H. W., Berzins, D. W., Moore, B. K., \& Charlton, D. G. (2009). Metal- ceramic alloys in dentistry: a review. Journal of Prosthodontics: Implant, Esthetic and Reconstructive Dentistry, 18(2), 188-194.

7. Liu, Q., Leu, M. C., \& Schmitt, S. M. (2006). Rapid prototyping in dentistry: technology and application. The international journal of advanced manufacturing technology, 29(3-4), 317-335.

8. Andersson, M., Carlsson, L., Persson, M., \& Bergman, B. (1996). Accuracy of machine milling and spark erosion with a CAD/CAM system. The Journal of prosthetic dentistry, 76(2), 187-193.

9. Joias, R. M., Tango, R. N., de Araujo, J. E. J., de Araujo, M. A. J., Saavedra, G. D. S. F. A., de Arruda Paes-Junior, T. J., \& Kimpara, E. T. (2008). Shear bond strength of a ceramic to Co-Cr alloys. The Journal of prosthetic dentistry, 99(1), 54-59.

10. Li, R. W. K., Chow, T. W., \& Matinlinna, J. P. (2014). Ceramic dental biomaterials and CAD/CAM technology: State of the art. Journal of Prosthodontic Research. 58.

11. Li, J., Chen, C., Liao, J., Liu, L., Ye, X., Lin, S., \& Ye, J. (2017). Bond strengths of porcelain to cobalt-chromium alloys made by casting, milling, and selective laser melting. The Journal of prosthetic dentistry, 118(1), 69-75.

12. Coornaert, J., Adriaens, P., \& De Boever, J. (1984). Long-term clinical study of porcelain-fused-to-gold restorations. Journal of Prosthetic Dentistry, 51(3), 338-342.

13. Arola, D. (2017). Fatigue testing of biomaterials and their interfaces. Dental Materials, 33(4), 367-381.

14. De Vasconcellos, L. G. O., Buso, L., Lombardo, G. H., Souza, R. O., Nogueira Júnior, L., Bottino, M. A., \& Özcan, M. (2010). Opaque Layer Firing Temperature and Aging Effect on the Flexural Strength of Ceramic Fused to Cobalt- Chromium Alloy. Journal of Prosthodontics: Implant, Esthetic and Reconstructive Dentistry, 19(6), 471477.

15. Keul, C., Stawarczyk, B., Erdelt, K. J., Beuer, F., Edelhoff, D., \& Güth, J. F. (2014). Fit of 4-unit FDPs made of zirconia and CoCr-alloy after chairside and labside digitalization-a laboratory study. Dental Materials, 30(4), 400407.

16. Serra-Prat, J., Cano-Batalla, J., Cabratosa-Termes, J., \& Figueras-Àlvarez, O. (2014). Adhesion of dental porcelain to cast, milled, and laser-sintered cobalt-chromium alloys: shear bond strength and sensitivity to thermocycling. The Journal of prosthetic dentistry, 112(3), 600-605.

17. Wang, H., Feng, Q., Li, N., \& Xu, S. (2016). Evaluation of metal-ceramic bond characteristics of three dental Co-Cr alloys prepared with different fabrication techniques. The Journal of prosthetic dentistry, 116(6), 916-923.

18. Beuer, F., Schweiger, J., \& Edelhoff, D. (2008). Digital dentistry: an overview of recent developments for CAD/CAM generated restorations. British dental journal, 204(9), 505-511.

Citation: Recep Kara (2021). Evaluation of Shear Bond Strenght of Porcelain to Cobalt-Chromium Alloy Fabricated with Different Methods After Thermocycling. South Asian Res J Oral Dent Sci, 3(1), 6-11. 